\section{STUDY ON RESISTANCE AND INTACT STABILITY BEHAVIOR OF PATROL BOAT USING AXE BOW HULL FORM TO SUPPORT SURVEILLANCE ACTIVITIES IN THE INDONESIA TERRITORIAL SEA}

Scopus

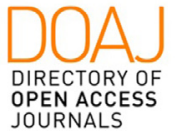

Crossref

\section{Adi Kurniawan Yusim}

Diponegoro University, Vocational School, Industrial Tech-

nology Department, Semarang, Indonesia

Key words: total resistance, axe bow hull form, intact stability, waterline spline type doi:10.5937/jaes0-29354

Cite article:

Windyandari, A., Yusim, A. K. (2021) STUDY ON RESISTANCE AND INTACT STABILITY BEHAVIOR OF PATROL BOAT USING AXE BOW HULL FORM TO SUPPORT SURVEILLANCE ACTIVITIES IN THE INDONESIA TERRITORIAL SEA, Journal of Applied Engineering Science, 19(3), 822-832, DOI:10.5937/jaes0-29354

Online aceess of full paper is available at: www.engineeringscience.rs/browse-issues 


\title{
STUDY ON RESISTANCE AND INTACT STABILITY BEHAVIOR OF PATROL BOAT USING AXE BOW HULL FORM TO SUPPORT SURVEILLANCE ACTIVITIES IN THE INDONESIA TERRITORIAL SEA
}

\author{
Aulia Windyandari*, Adi Kurniawan Yusim \\ Diponegoro University, Vocational School, Industrial Technology Department, Semarang, Indonesia
}

As a sovereign maritime country, Indonesia has an obligation to protect, maintain, and manage marine and fishery resources. Patrol boats as the primary means of monitoring marine and fishery resources are needed in response to several problems and threats that may occur, such as illegal fishing, destructive fishing, violations of zoning in fisheries conservation areas and others. Apart from having to be adequate on the number of units, the patrol boats must also have suitable technology to support pursuit operations and suppress violations. The main objective of this research is to investigate the total resistance and intact stability behavior of the developed axe bow hull geometry for the patrol boat hull. The preliminary design is started with the determination of the principal dimension of the patrol boat. Then the hull geometry configurations were made with the variation of the depth of bow and the water line spline type. In the case of the depth of bow, the bow with the additional depth of $30 \%, 40 \%$ and $50 \%$ of the draft was investigated. Otherwise, the water line spline type was configured as convex spline, concave spline and straight spline. According to the numerical analysis, the axe bow hull with the depth of bow of $30 \%$ and the straight spline type was presented the smallest total resistance performance. However, in the case of intact stability performance, all developed axe bow hull presented a similar righting moment lever arm (GZ curve). It is indicated that the total resistance of the axe bow hull is influenced by the depth of bow and water line spline type. Furthermore, those variables have a slight influence on intact stability performance.

Key words: total resistance, axe bow hull form, intact stability, waterline spline type

\section{INTRODUCTION}

The number of patrol boats owned by the maritime and fisheries ministry is 34 vessels. These ships are grouped into four classes which are determined based on operational factors. The boat specification data are consist of the length of the boat, cruise speed, cruising capability, effective radar range and operational area capability. The qualification of the patrol boat ability in each class group on operational factors can be seen in Table 1. Based on data from the directorate of marine and fisheries resources, Class A consisted of four boats of 3 years old. Class $B$ consisted of two boats with 1 unit over ten years old. Class $C$ consisted of eleven boats with 5 unit more than ten years old. Class $D$ and $E$ consisted of 12 and 5 boats, respectively, and all of the boats are over ten years old. The condition of the patrol boat fleet indicates that the monitoring and safeguarding activities of marine and fisheries resources are carried out with all of their limitations, the lack of ship units, age and technology conditions adopted by the existing patrol vessels. The small number of boats, the technology, and the boat age have caused the shortage of surveillance service capacity. The shortage capacity of the surveillance service fleet must be improved and responded to the government program such as the ship procurement/renovation programs, the studies on the optimal fleet capacity and the research activities on the patrol boat technology. All development program should follow the needs and characteristics of the operational area. Therefore, developing an advanced hull form is very important to improve the protection and surveillance activities capability.

Accordingly, the axe bow hull form was proposed as an

Table 1: Qualification of the operational capability of the patrol boat

\begin{tabular}{|c|c|c|c|c|c|c|}
\hline No & Class & $\begin{array}{c}\text { Boat Length } \\
\text { (meter) }\end{array}$ & $\begin{array}{c}\text { Cruising } \\
\text { Speed (Knot) }\end{array}$ & $\begin{array}{c}\text { Cruising } \\
\text { Time (Hour) }\end{array}$ & range (Nm) & $\begin{array}{c}\text { Operational Area Capability } \\
\text { (Sea state) }\end{array}$ \\
\hline 1 & $\mathrm{~A}$ & $>50$ & 17 & 120 & 45 & $4-5$ \\
\hline 2 & $\mathrm{~B}$ & $40-50$ & 16 & 72 & 35 & 4 \\
\hline 3 & $\mathrm{C}$ & $30-40$ & 17 & 72 & 30 & 3 \\
\hline 4 & $\mathrm{D}$ & $20-30$ & 17 & 36 & 20 & 3 \\
\hline 5 & $\mathrm{E}$ & $15-20$ & 16 & 24 & 10 & 2 \\
\hline
\end{tabular}


alternative design to respond to the improvements required in terms of the number of boats, the technology, and the age of the existing boats. The aim of this research is to investigate the total resistance and the intact stability performance of the developed axe bow hull form. The influence of design configuration includes the depth of bow and the water line spline type to both performances was made. The comparison between the geometry of the developed hull is also presented.

The outline of the paper is presented the literature review of the characteristics of axe bow hull form and any fast boat technology in the literature review on the development of the monohull fast boat hull form. The conceptual hull design development to obtain the geometry hull through the exploration and modification of the parent hull are presented in the conceptual design of the axe bow hull form. The calculations procedure of the boat resistance and the intact stability behavior described the procedure and method of the total resistance calculation and the intact stability performance estimation of the developed axe bow hull form. The results and discussion were explained, in result and discussions, the influence of the design parameters, which consists of the depth of bow and the waterline spline type, to the resistance and intact stability performance. Finally, the conclusion and recommendation were made as regards the analysis results.

\section{THE LITERATURE REVIEW ON THE DEVELOPMENT OF THE MONOHULL FAST BOAT HULL FORM}

The use of monohull type as a hull form for fast boats has shown an increasing trend in the decades. Patrol boats, survey ships and warships require fast monohuII designs to support their operations. The maneuvering characteristics of the fast patrol boats, especially in terms of vertical acceleration, are the essential factors in determining the operability of ships in the seaways environment. Several studies have shown that the very high vertical acceleration, especially in the work area on the boat, causes the crew to reduce the vessel speed. Consequently, the fast boat never reached the defined maximum speed performance. A reduction speed action is a responsible option that should be made to eliminate seasickness and uncomfortable situations due to the high vertical acceleration on the maximum speed conditions. Therefore, improving the vertical motion velocity and acceleration should be made by developing hull geometry for the fast vessel.

The Enlarged Ship Concept (ESC) is an early concept developed by Keuning and Pinkster, [2], [3], by increasing significantly the vessel length, which is about $25 \%$, and the other parameters are still the same, such as vessel breadth, load capacity, service speed and payload, Fig. 1. This modification can improve vessel resistance performance by reducing the total resistance by $30 \%$ and better maneuvering behavior.

However, the production cost is slightly increasing about $3 \%-5 \%$. Increasing the ship length can allow the main work area to shift to an optimal position along the ship

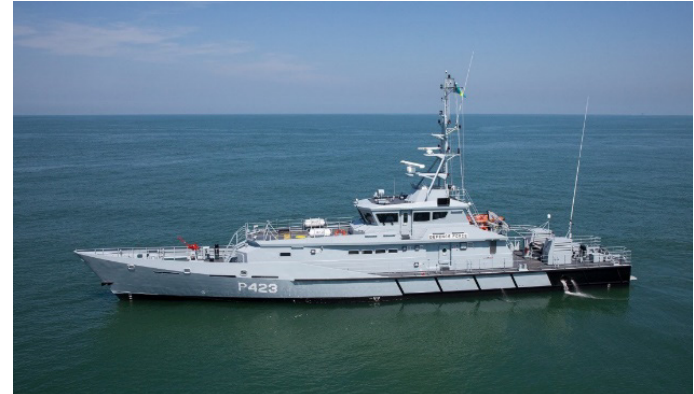

Figure 1: Stan Patrol 4207 with enlarged ship type hull form

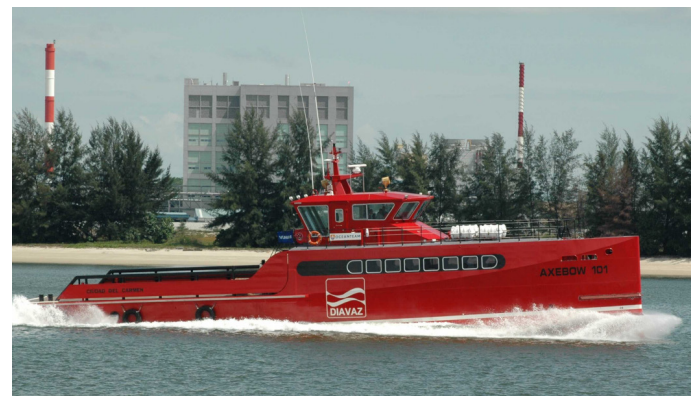

Figure 2. The Patrol Boat with axe bow type hull form

length. Therefore the ship operability has improved. Due to the additional space on the ESC hull form, especially the ship bow, this section can be modified to prevent the excitation force due to large waves.

Accordingly, a bow design with a very deep forefoot, very small flares, high deadrise, small volume and high sheer was introduced. By reducing the non-linear Froude-Krylov forces, and the forces associated with hydrodynamic lift, the peak value of vertical acceleration can be reduced. This hull form geometry design was launched in 2001, and it is known as the axe bow type hull form (AXE Bow Concept hull form), Fig. 2.

The axe bow type is a development of the ESC hull form type by providing modifications to the bow part. The front section of the axe bow-type hull does not have a flare shape, only a vertical upright side. The bow (stem) is a vertical line with a sharp front. On the upper deck sideline, there is a significant addition of sheer. While at the bottom, the bottom line is drawn lengthwise in the direction of the bow. The additional length of the bow depth is downward curved, which is similar to the shape of the sheer on the upper deck. The purpose of this modification is to reduce the wave excitation force and hydrodynamic lift. In the heave and pitch motion, this bow can be described as a soft spring system. Experimental testing conducted by Keuning, [5], showed that there is a good improvement in seakeeping compared to the shape of the ESC hull, especially the vertical acceleration on the bow and the wheelhouse is decreased significantly. The shape of the axe-bow type lines plan, which is developed by Keuning, can be seen in Figure 3.

Several articles have been reviewed to support the development of the axe-bow type hull form for patrol boats. These articles relate to studies of the performance of the axe-bow and the other monohull types that are used for 


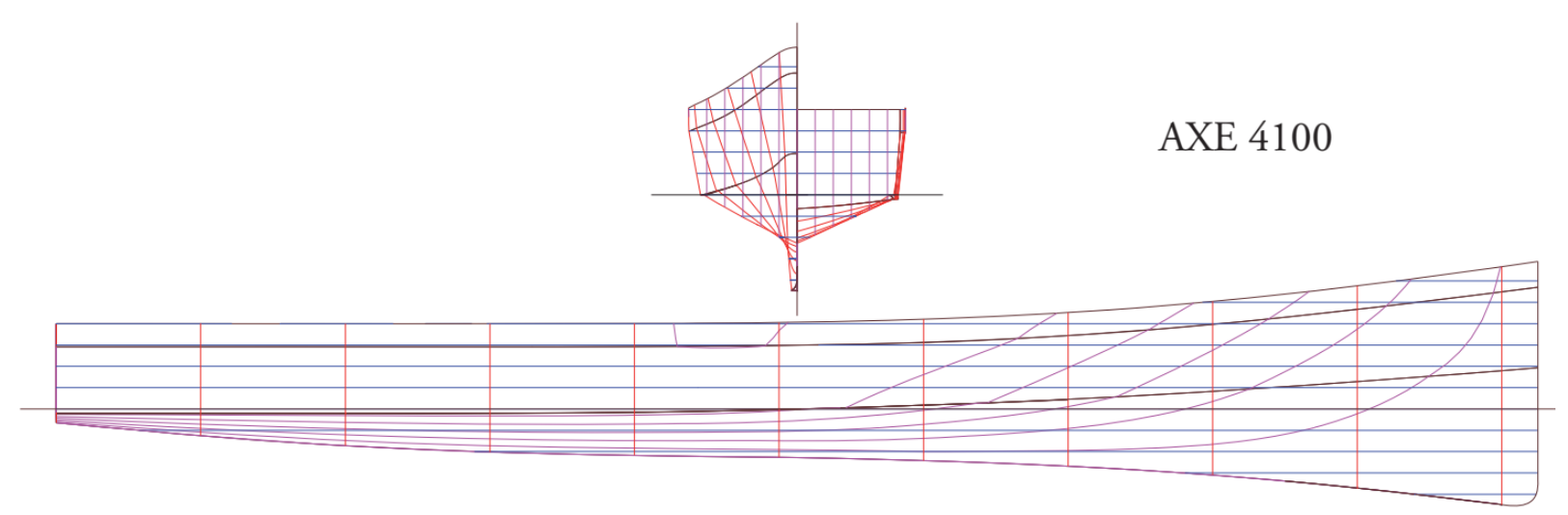

Figure 3: The lines plan of Axe bow type hull Form "AXE 4100" developed by Keuning

the fast boats with service speeds above 20 knots.

Keuning and Van Walree, [6], have carried out a comparative study of the hydrodynamic behavior of three fast patrol boats using special hull forms. Three types of hull form are used, namely the enlarged ship type (ESC), the axe bow type and the wave-piercing type. The study results show that the axe bow type performs better in head sea conditions than the ESC type and the wave-piercing type. In the stern quartering sea, the axe bow and the ESC types do not differ significantly. The wave-piercing type experiences severe deck wetness and green water load in head sea conditions. The axe bow type is capable of achieving $100 \%$ operability throughout the year and also can be used in the North Sea at the maximum service speeds of 35 - 50 knots. In several other studies, Keuning has studied the non-linear behavior of monohull fast boat motion, [7], [8], and the effect of bow shape on fast boat performance, [9], [10], [11].

Gelling, J.L., [12], have conducted an analysis of the application of the axe-bow type hull form on the yacht designs. The results have shown that the axe bow type has excellent seakeeping characteristics where the slamming is not visible on the yacht. The boat resistance characteristics at high-speed conditions also decrease. It can be explained that the application of the long waterline and the slender body has provided a streamlined flow that might reduce the wave-making resistance. The low resistance behavior has provided a higher service speed with lower engine power.

Consequently, yacht construction can be made from steel material. The better resistance performance in the service speed conditions can also be found compared to the conventional semi-displacement hull type and the planing hull type. Additionally, the axe bow type hull can provide an effect positively on intact stability and reduce the risk of problems caused by structural fatigue.

In the more recent publication, several literature works have presented the research on the other hull form type for the fast boat. Poundra et al., [13], study on the optimization of the trimaran yacht hull configuration. Ferrandis et al., [14], study on the influence of large hull deformation on the motion response of fast catamaran. Dumortier et al., [15], investigate the power prediction tool with the measured data for the design of a military boat. De Luca and Pensa, [16], study on the seakeeping characteristics of the Naples Systematic Series (NSS). Caramatescu and Mocanu, [17], study on the wave impact stress on the composite hull. Niklas and Pruszko, [18], conducted the CFD seakeeping simulations of the modifications of V-shaped Bulbous Bow to X-Bow hull form. Tavakoli et al., [19], study on the dynamic of the planing hull in regular waves by comparing the experimental measurement and numerical methods. Bilandi et al., [20], study on the performance of two swept step hull form at high speeds with the experimental and numerical approach. Yanuar et al. [21] have investigated the drag reduction of X-pentamaran with the configurations of hull separation and asymmetric hull form.

Regarding the above development, this paper investigates the resistance and intact stability behavior of the developed axe bow hull form for the patrol boats. The modification has been made in the case of the depth of the bow and the spline type of the fore part water line. Furthermore, the influence of both parameters on the resistance and intact was investigated.

\section{The conceptual design of the axe bow hull form}

The initial step for the conceptual design of the axe bow hull was begun with the collection of the existing patrol boat as the reference patrol boat to determine the principal dimension, Table 1. From the reference boat data, the linear regression equation model has been created to determine the principal dimension of the developed boat. The generated linear regression equations have been developed to define the relations of boat displacement with the other principal dimension, which includes length overall (LOA), breadth, draught and maximum service speed, Table 2 . The principal dimension of the developed axe bow patrol boat can be seen in Table 3 . The explorations of the lines of the axe-bow hulls have been conducted through the modification of the depth of the bow (DoB) and the spline type of the hulls water lines. The configurations of the additional bow depths have been determined of $30 \%, 40 \%$ and $50 \%$ of the midship draft, Fig. 4. Otherwise, the spline types at the fore-end of the hull have been defined as concave type, 
Table 1: The reference boats to determine the principal dimension of the axe bow patrol boat

\begin{tabular}{|c|c|c|c|c|c|c|}
\hline No & Vessel Name & Displacement (tons) & LOA $(\mathbf{m})$ & $\mathbf{B}(\mathbf{m})$ & $\mathbf{T}(\mathbf{m})$ & Vmax (knot) \\
\hline 1 & Argos & 97 & 27.00 & 5.90 & 2.80 & 26.00 \\
\hline 2 & BAP Río Chira (PC-223) & 147 & 36.00 & 6.40 & 1.80 & 18.00 \\
\hline 3 & BRP Ilocos Norte & 120 & 36.20 & 6.70 & 3.90 & 25.00 \\
\hline 4 & Centauro & 94 & 37.00 & 7.00 & 1.70 & 32.00 \\
\hline 5 & Erle (P999) & 160 & 36.50 & 6.20 & 1.50 & 32.50 \\
\hline 6 & HMTSS Te Mataili & 162 & 31.50 & 8.10 & 1.80 & 20.00 \\
\hline 7 & KRI Sibarau & 146 & 32.76 & 6.20 & 1.90 & 21.00 \\
\hline 8 & KRI Silea & 146 & 32.76 & 6.20 & 1.90 & 21.00 \\
\hline 9 & PMSS Rafaqat & 168 & 34.00 & 6.40 & 2.20 & 29.50 \\
\hline 10 & PSKR-402 & 120 & 35.35 & 6.79 & 1.74 & 50.00 \\
\hline 11 & Skarv (P990) & 160 & 36.50 & 6.20 & 1.50 & 32.50 \\
\hline 12 & Šolta (OB-02) & 142 & 32.00 & 6.75 & 2.70 & 30.00 \\
\hline 13 & T.991 & 186 & 38.70 & 6.49 & 1.81 & 27.00 \\
\hline 14 & TCSG-109 & 97 & 31.50 & 6.70 & 1.42 & 48.00 \\
\hline 15 & USCGC Matagorda & 168 & 34.00 & 6.40 & 2.20 & 29.50 \\
\hline
\end{tabular}

Table 2: The linear regression equation for determining the developed hull principal dimensions

\begin{tabular}{|c|c|}
\hline Principal Dimension & Linear Regression Equation \\
\hline Length overall (LOA) & $L O A=28.646+0.049(\Delta)$ \\
\hline Breadth (B) & $B=6.599-0.00026(\Delta)$ \\
\hline Draught (T) & $T=2.689-0.00448(\Delta)$ \\
\hline Maximum Speed (Vmax) & $V \max =47.112-0.12527(\Delta)$ \\
\hline
\end{tabular}

Table 3: The principal dimension of the developed axe-bow hull form

\begin{tabular}{|c|c|}
\hline \multicolumn{2}{|c|}{ Main Dimension } \\
\hline Length overall (LOA) & $35.25 \mathrm{~m}$ \\
\hline Breadth $(\mathrm{B})$ & $6.56 \mathrm{~m}$ \\
\hline Draught $(\mathrm{T})$ & $2.08 \mathrm{~m}$ \\
\hline Maximum Speed $($ Vmax $)$ & $30.20 \mathrm{knot}$ \\
\hline Displacement $(\Delta)$ & 135 tons \\
\hline
\end{tabular}

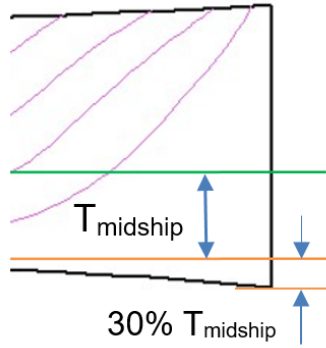

(a)

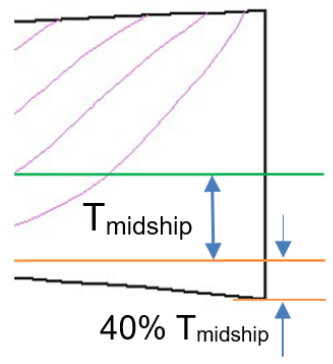

(b)

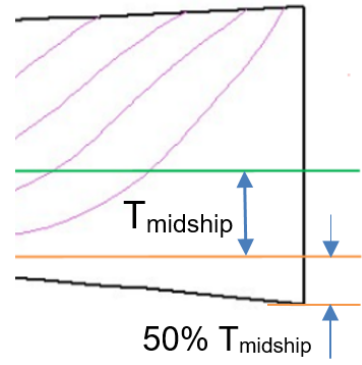

(c)

Figure 4: The configuration of the depth of bow: [a] 30\% of draught; [b] $40 \%$ of draught; [c] 50 of draught

convex type and straight type, Fig. 5.

The spline types have been selected as the hull form design parameters because the fore-end spline line might influence the magnitude of the waterline half-angle of entrance, Fig. 6 . The larger angle of entrance might shift the displacement close to the water surface. This condi- 


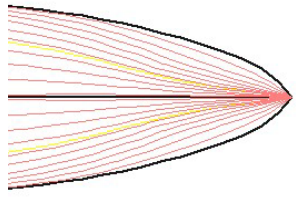

(a)

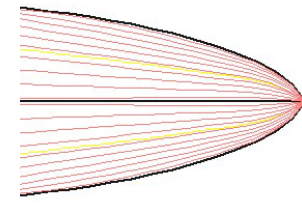

(b)

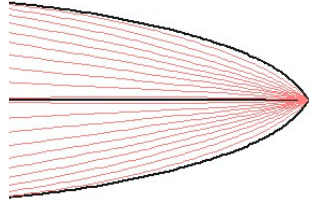

(c)

Figure 5: The configuration of the spline: [a] concave type; [b] convex type; [c] straight type

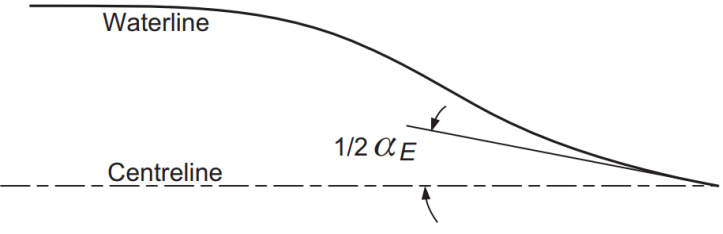

Figure 6: The half-angle of entrance of the hull waterline

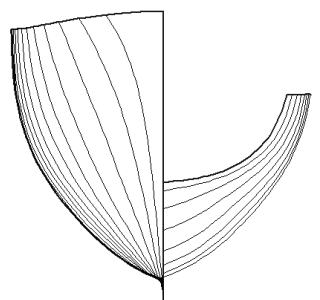

(a)

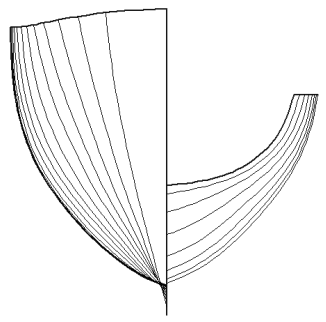

(d)

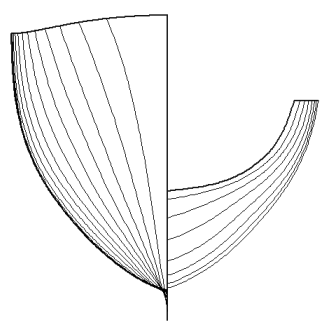

(g)

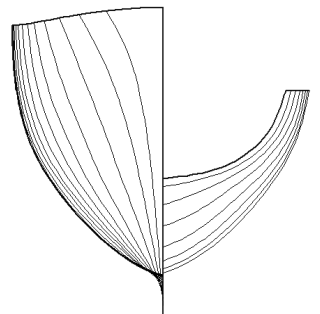

(b)

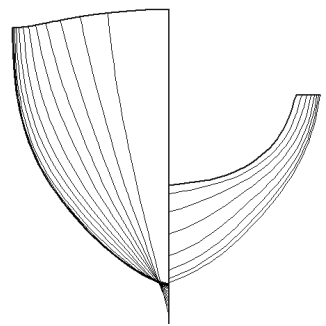

(e)

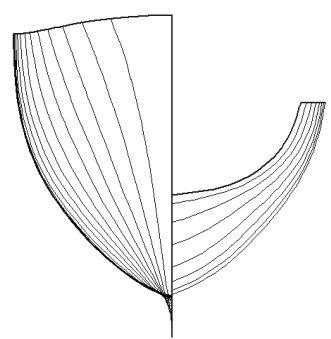

(h)

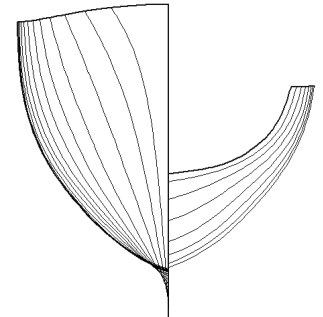

(c)

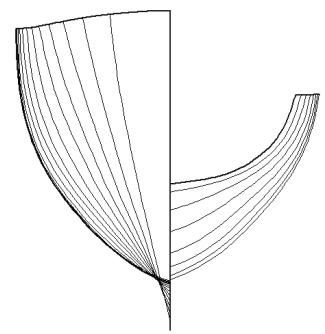

(f)

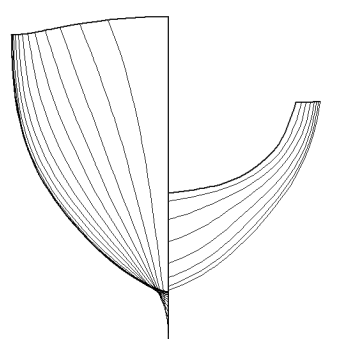

(i)

Figure 7: The design variation body plan of the developed axe bow hull

tion will generate more wave making that increased the hull resistance. Therefore the combinations of both parameters have generated nine kinds of hull design prototype that its body plan can be seen in Fig. 7 .

\section{THE CALCULATIONS PROCEDURE OF THE BOAT RESISTANCE AND THE INTACT STABILITY BEHAVIOR}

\section{The slender body method for resistance estimation}

The resistance characteristics of the developed axe bow should be investigated to recognize the influences of the two design parameters to fulfil the power requirement of the boat propulsion. Since the axe bow body can be identified as a long and slim vessel hull, therefore the slender body method was adopted for the estimation of resistance performance. The minimum slenderness ratio (length per beam), as a requirement for resistance prediction in the slender body method, depends on the Froude number. In the low Froude number, the slender body method might be applied for the vessel body with a slenderness ratio of 4.0. However, the minimum slenderness ratio, usually in the range of 5.0 to 7.0.

The slender body method is initially developed from the 


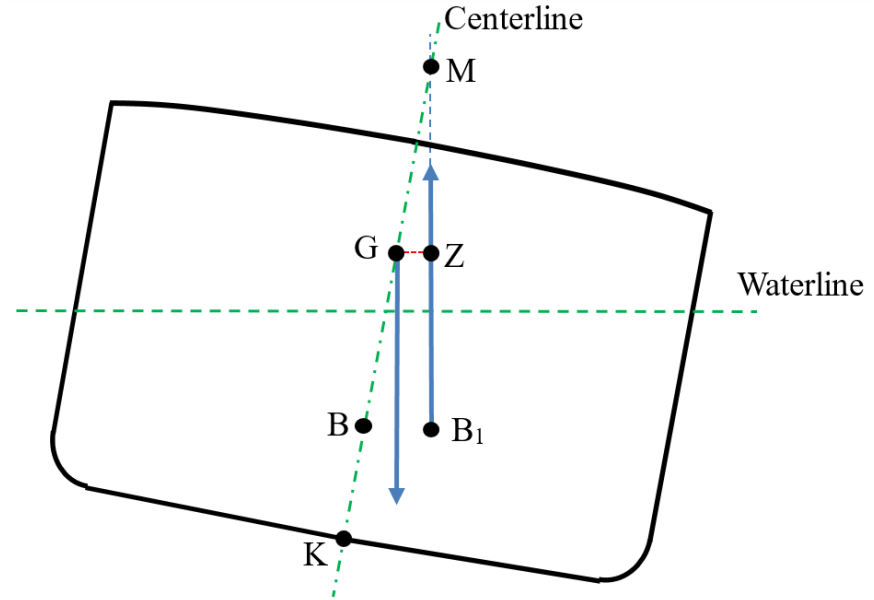

Figure 8: The righting lever arm (GZ) and the metacenter point

thin ship theory by Mitchell [22], Wigley [23], and Eggers [24]. The original methods have been improved by Tuck [25] and Couser [26], and this method can be used to estimate the wave resistance of many hull form. The slender body method also can be adopted for the round bilge and the chine hull form. However, the investigated hull should be slender and symmetric on its centerline. Since the method only predicts the wave-making resistance, the total resistance can be estimated by adding the viscous resistance which is calculated using ITTC'57, [27]. The Holtrop and Mennen form factor has been selected for the calculation of total resistance.

\section{The GZ curve and intact stability criteria}

The vessel body should be capable of returning to its initial position due to the exerted external load on the floating condition. The stable hull response motion, while returning to its initial position, is generated from the righting lever arm that has been occurred because of the shifted center buoyancy on the heeling position. The positive lever arm generates a positive righting moment. Otherwise, the vessel might capsize due to the negative ones. Therefore the intact stability performance is an essential factor that should be fulfilled in order to ensure the safety of the vessel.

In the still water condition, the initial stability of the floating bodies can be measured with the height of the metacenter (GM0). The metacenter height is the distance of the boat center of gravity $(G)$ to the metacenter point $(M)$, Fig. 8. The metacenter point is the imaginary point that is located at the intersection of the even keel condition buoyancy force line with the heeling one. The positive metacenter is obtained when the metacenter point position is higher than the center of gravity point. The metacentre position is determined by the inertial moment of the water plane and the boat displacement. Otherwise, the large-angle stability is measured with the GZ curve. The GZ curve represented the magnitude of righting arm that is generated from the set of the cross curve (KN curve) on each heel angle.
The calculated GZ curve should comply with the intact stability criteria. There are many kinds of intact stability criteria, such as the HSC Code, IMO, MARPOL, etc. Those criteria were developed to give a standard requirement for the intact stability as regards to the vessel type, the cargo type, and the operational characteristics. The US Coast Guard, Part 170, Stability requirements for all inspected vessels have been adopted to evaluate the developed axe bow hull form. The US coast guard criteria for the developed axe bow can be defined as follow:

1. The required $\mathrm{GM}$ against wind pressure calculation should be evaluated

2. The GMt should be greater than the required GM against wind pressure

3. The initial $\mathrm{GMt} \geq 0.149 \mathrm{~m}$

4. The Value of $G Z \geq 0.201 \mathrm{~m}$

5. The angle at which $\mathrm{GZ}$ is a maximum positive value $\geq 25^{\circ}$

6. The area below the $\mathrm{GZ}$ curves up to $30^{\circ} \geq 3.151 \mathrm{~m}$. deg.

7. The area below the $\mathrm{GZ}$ curves up to $40^{\circ} \geq 5.157$ m.deg.

8. The area below the $\mathrm{GZ}$ curve from $30^{\circ}$ to $40^{\circ} \geq 1.719$ m.deg.

9. The area below the $\mathrm{GZ}$ up to the angle of maximum $\mathrm{GZ} \geq 3.150$ m.deg.

10. The angle of vanishing stability $\geq 35^{\circ}$

11. The angle of down flooding (DF) $\geq 20^{\circ}$

\section{RESULT AND DISCUSSIONS}

\section{Resistance behavior of the developed axe bow hull form}

The variation of depth of bow and the spline type on the developed hull have been examined to estimate its influence on the resistance behavior. The results show that the wave resistance coefficient is slightly influenced by the depth of bow, Fig. 9. The depth of bow of $50 \%$ was shown more enormous resistance than the smaller ones on the service speed 9 to 12 knot. However, on the service over than 12 knots, the larger depth of bow has presented the smaller wave resistance coefficient. It is indicated that the larger depth of bow has a slight-

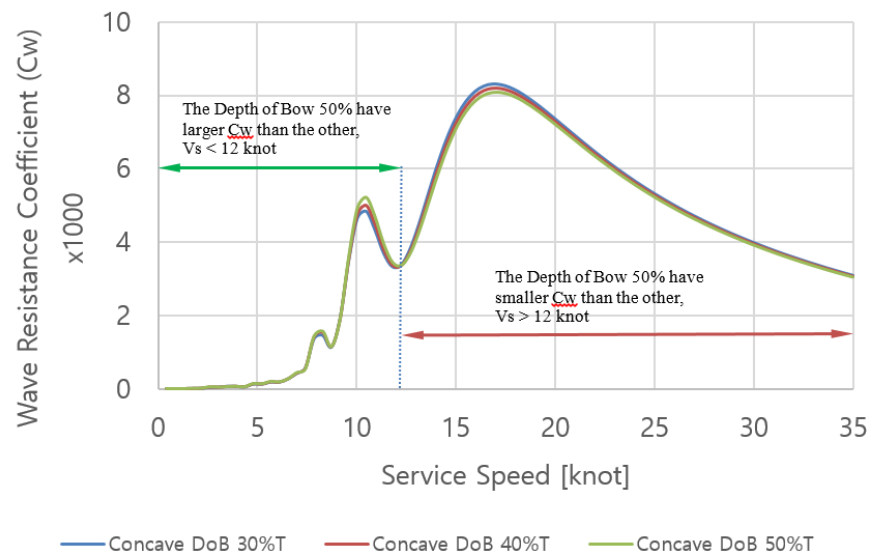

Figure 9. The wave resistance coefficient on the variation of the depth of bow 


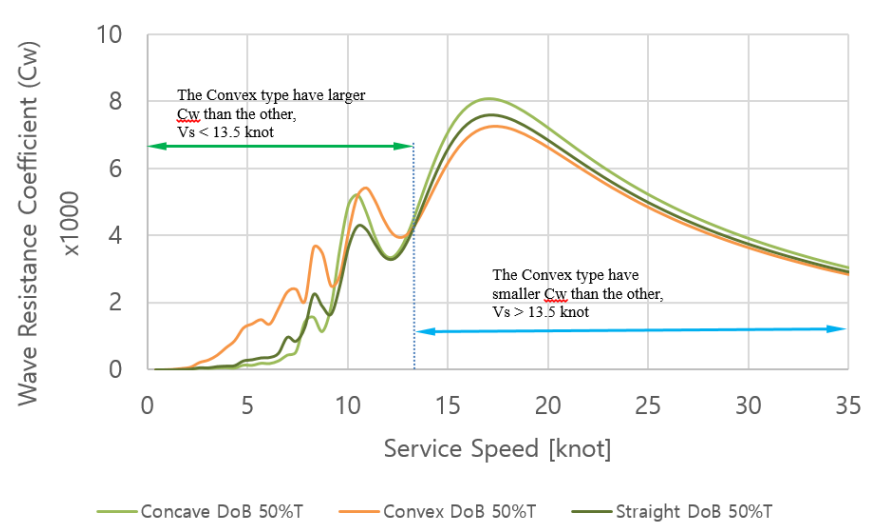

Figure 10: The wave resistance coefficient on the variation of the spline type

ly positive influence on the wave-making resistance on the high-speed condition. Otherwise, a similar or higher value of the wave resistance coefficient was generated.

In the case of the variation of spline type, the results show that the convex type has presented a larger wave resistance coefficient than the others on the service speed below 13.5 knots, Fig. 10. However, on the service speed over $13.5 \mathrm{knots}$, the influence of the convex type on the wave resistance factor became smaller than the others. It is indicated that the convex spline has effectively reduced the wave-making resistance on the higher service speed. However, the concave type was shown as an effective spline on the low service speed ( $\mathrm{Vs}<13.5$ knots). Therefore the convex type with the depth of bow $50 \%$ has the lowest wave resistance factor on the high service speed (Vs>13.5 knots). Furthermore, the concave type with the depth of bow $30 \%$ is the lowest wave resistance factor on the low service speed ( $V_{s}<13.5$ knots).

Since both parameter variation has influenced the wave resistance coefficient, the total resistance also should be affected by the parameters. Figure 11 shows that the total resistance of the concave type with the variation of depth of bow has presented a similar value. However, it is still recognized that the depth of bow $30 \%$ has shown a lower value than the others, especially on the high service speed. Although the depth of bow $30 \%$, on the wave resistance coefficient, is recognized to have a larger coefficient. Otherwise, the hull type has better total resis-

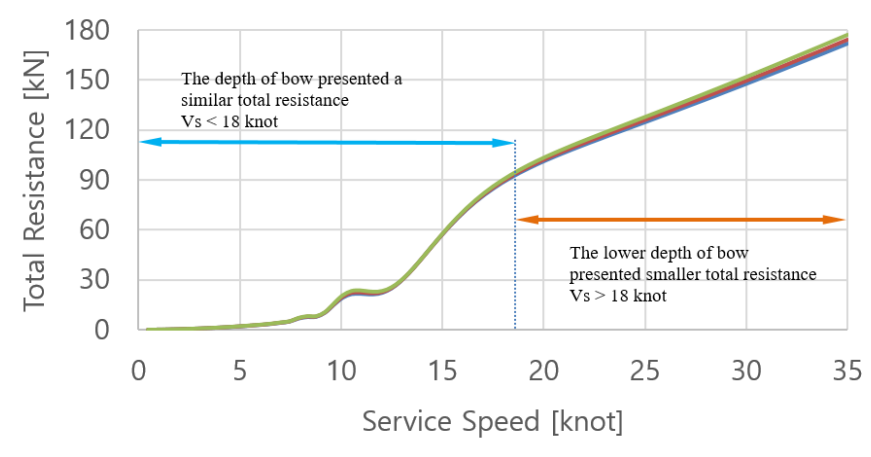

Concave DoB 30\%T Concave DoB 40\%T Concave DoB 50\%

Figure 11: The total resistance on the variation of the depth of bow

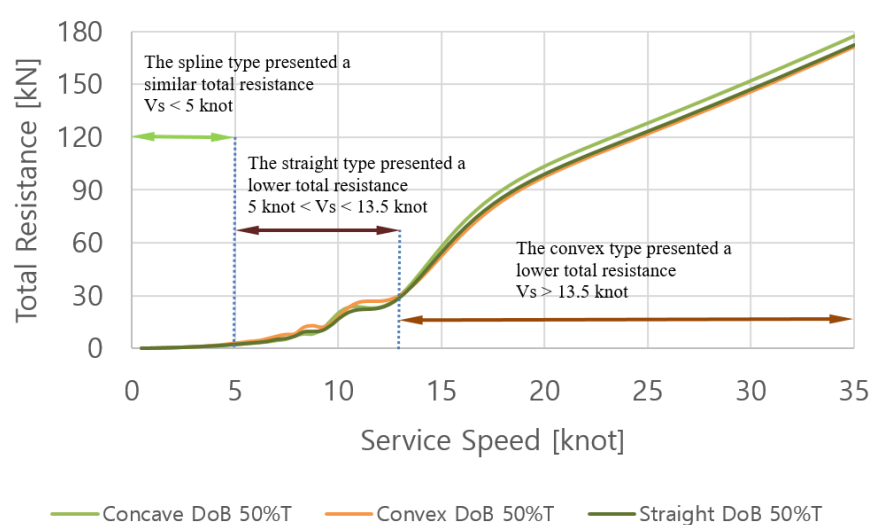

Figure 12: The total resistance on the variation of the spline type

tance than the others. It is indicated that the influence of the variation of the depth of bow on the wave resistance coefficient does not have a significant contribution to the total resistance performance.

In the case of the spline type variation, Figure 12 has easily been recognized that the spline type variation influences the total resistance. Although the total resistance was identified as similar among the others, on the low service speed $\left(V_{s}<5\right.$ knots). The straight type has presented the lowest total resistance on the slightly moderate service speed (Vs=5 13.5 knot). However, the convex type have been the lowest total resistance when the service speed is increased over 13.5 knots. Those trends of the phenomena are similar to the changes in the wave resistance coefficient behavior. It is indicated that the spline type has influenced the magnitude of the total resistance because the spline type has a significant influence on the magnitude of the wave resistance coefficient. Regarding the results, it can be concluded that the convex type with the depth of bow $30 \%$ T has the lowest total resistance on the high service speed, and the straight type with the depth bow of $30 \% \mathrm{~T}$ was the lowest one on the slightly moderate service speed. Nevertheless, all of the developed hull forms have similar total resistance on the low service speed.

\section{Intact stability behavior of the developed axe bow hull form}

The performance on the intact stability can be measured with the GZ value in every step of heel angles. The modification of the hull geometry can produce the different $G Z$ curves, which is mean the intact stability performance was modified. Figure 13 have presented that the depth of bow does not have a significant influence on the intact stability performance. Therefore the generated GZ curve due to the variation of the depth of bow has shown a similar line.

In the same case with the depth of bow, Figure 14 also presented that the variation of spline type does not have a significant influence on the GZ curve. However, these conditions are theoretically acceptable since the modification do not significantly change the shape of the de- 


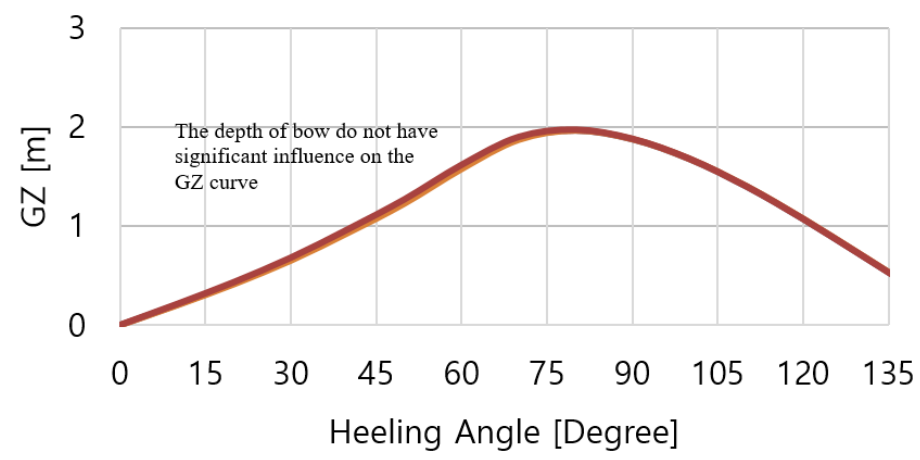

Concave DoB 40\% Concave DoB 50\% Concave DoB 30\%

Figure 13: The stability curves (GZ) on the variation of the depth of bow

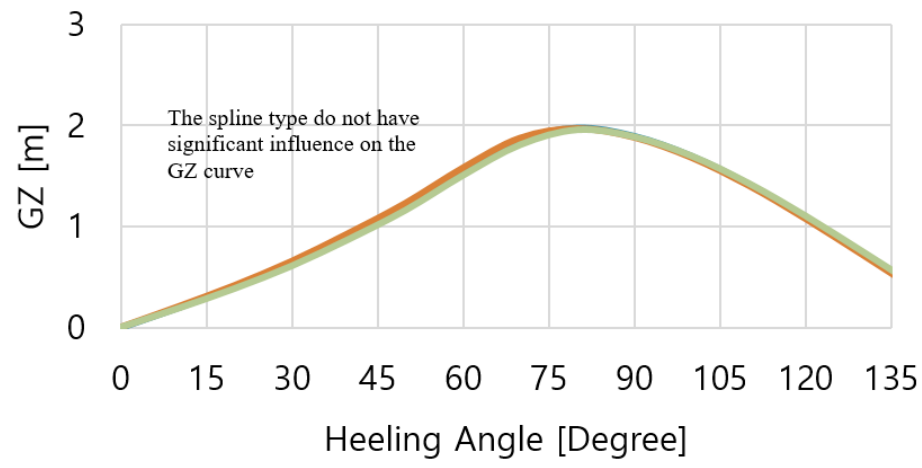

Straight DoB 50\% Concave DoB 50\% Convex DoB 50\%

Figure 14: The stability curves (GZ) on the variation of the spline type

Table 3: Comparison of the concave type model on the US coast guard criteria

\begin{tabular}{|c|c|c|c|c|c|}
\hline \multirow{2}{*}{ The US coast guard Criteria } & \multirow{2}{*}{ Required } & \multicolumn{3}{|c|}{ Concave Type Model } & \multirow{2}{*}{ Status } \\
\hline & & $30 \% \mathrm{~T}$ & $40 \% \mathrm{~T}$ & $50 \% \mathrm{~T}$ & \\
\hline Required GM & - & 0.60 & 0.63 & 0.66 & Passed \\
\hline Initial GMt & Required GM & 0.95 & 1.14 & 1.31 & Passed \\
\hline Initial GMt & $0.149 \mathrm{~m}$ & 0.95 & 1.14 & 1.31 & Passed \\
\hline The value of GZ & $0.201 \mathrm{~m}$ & 1.69 & 1.92 & 2.15 & Passed \\
\hline Angle of GZ max & $25 \mathrm{deg}$ & 78 & 78.6 & 79 & Passed \\
\hline Area $0^{\circ}$ to $30^{\circ}$ & $3.151 \mathrm{~m} . \mathrm{deg}$ & 7.87 & 9.29 & 10.65 & Passed \\
\hline Area $0^{\circ}$ to $40^{\circ}$. or DF point & 5.156 m.deg & 14.59 & 17.10 & 19.49 & Passed \\
\hline Area $30^{\circ}$ to $40^{\circ}$. or DF point & $1.718 \mathrm{~m} . \mathrm{deg}$ & 6.72 & 7.80 & 8.84 & Passed \\
\hline Area up to max GZ & $3.150 \mathrm{~m} . \mathrm{deg}$ & 7.87 & 9.29 & 10.65 & Passed \\
\hline Angle of vanishing stability & 35 deg. & 90 & 90 & 90 & Passed \\
\hline DF angle & $20 \mathrm{deg}$ & 57 & 57 & 57 & Passed \\
\hline
\end{tabular}

veloped hull form. Although the variation of both parameters does not significantly recognize on the GZ curve, the estimation of the intact stability performance has been presented and compared with the acceptance criteria of US Coast Guard regulation in Table 3 - Table 5.

According to Table 3, it can be seen that all of the concave type has been accepted with the US coast guard criteria. Although in Fig. 13, the influence of the depth of bow on the intact stability performance cannot be recognized. Table 3 have presented that the hull with the depth of bow of $50 \% \mathrm{~T}$ has a larger number than the others. It is indicated that the larger depth of bow has better intact stability performance amongst others. This tendency can also be seen in the convex type and the straight on Table 4 and Table 5.

The influence of the spline type variation on the intact stability performance also can be identified in Table 3 Table 5. It can be seen that the concave type has shown a larger magnitude than the other spline type, especially on the criteria of the area below the GZ curve. There- 
Table 4: Comparison of the convex type model on the US coast guard criteria

\begin{tabular}{|c|c|c|c|c|c|}
\hline \multirow{2}{*}{ The US coast guard Criteria } & \multirow{2}{*}{ Required } & \multicolumn{2}{|c|}{ Concave Type Model } & \multirow{2}{*}{ Status } \\
\cline { 3 - 5 } & & $\mathbf{3 0 \%} \mathbf{~ T}$ & $\mathbf{4 0 \%} \mathbf{~ T}$ & $\mathbf{5 0 \%} \mathbf{~ T}$ & \\
\hline Required GM & - & 0.57 & 0.60 & 0.63 & Passed \\
\hline Initial GMt & Required GM & 0.89 & 1.06 & 1.23 & Passed \\
\hline Initial GMt & $0.149 \mathrm{~m}$ & 0.89 & 1.06 & 1.23 & Passed \\
\hline The value of GZ & $0.201 \mathrm{~m}$ & 1.70 & 1.92 & 2.14 & Passed \\
\hline Angle of GZ max & $25 \mathrm{deg}$ & 79.5 & 79.5 & 80 & Passed \\
\hline Area $0^{\circ}$ to $30^{\circ}$ & $3.151 \mathrm{~m} . \mathrm{deg}$ & 7.38 & 8.70 & 10 & Passed \\
\hline Area $0^{\circ}$ to $40^{\circ}$. or DF point & $5.156 \mathrm{~m} . \mathrm{deg}$ & 13.72 & 16.05 & 18.34 & Passed \\
\hline Area $30^{\circ}$ to $40^{\circ}$. or DF point & $1.718 \mathrm{~m} . \mathrm{deg}$ & 6.34 & 7.35 & 8.34 & Passed \\
\hline Area up to max GZ & $3.150 \mathrm{~m} . \mathrm{deg}$ & 7.38 & 8.70 & 10 & Passed \\
\hline Angle of vanishing stability & $35 \mathrm{deg}$. & 90 & 90 & 90 & Passed \\
\hline DF angle & $20 \mathrm{deg}$ & 56 & 56.5 & 57 & Passed \\
\hline
\end{tabular}

Table 5: Comparison of the straight type model on the US coast guard criteria

\begin{tabular}{|c|c|c|c|c|c|}
\hline \multirow{2}{*}{ The US coast guard Criteria } & \multirow{2}{*}{ Required } & \multicolumn{2}{|c|}{ Concave Type Model } & \multirow{2}{*}{ Status } \\
\cline { 3 - 5 } & & $\mathbf{3 0 \%} \mathbf{~ T}$ & $\mathbf{4 0 \%} \mathbf{~}$ & $\mathbf{5 0 \%} \mathbf{~}$ & \multirow{2}{*}{ Passed } \\
\hline Required GM & - & 0.59 & 0.66 & 0.65 & Passed \\
\hline Initial GMt & Required GM & 0.93 & 1.10 & 1.28 & Passed \\
\hline Initial GMt & $0.149 \mathrm{~m}$ & 0.93 & 1.10 & 1.28 & Passed \\
\hline The value of GZ & $0.201 \mathrm{~m}$ & 1.71 & 1.97 & 2.16 & Passed \\
\hline Angle of GZ max & $25 \mathrm{deg}$ & 79 & 79 & 79 & Passed \\
\hline Area $0^{\circ}$ to $30^{\circ}$ & $3.151 \mathrm{~m} . \mathrm{deg}$ & 7.67 & 9.03 & 10.39 & Passed \\
\hline Area $0^{\circ}$ to $40^{\circ}$. or DF point & $5.156 \mathrm{~m} . \mathrm{deg}$ & 14.24 & 16.67 & 19.03 & Passed \\
\hline Area $30^{\circ}$ to $40^{\circ}$. or DF point & $1.718 \mathrm{~m} . \mathrm{deg}$ & 6.57 & 7.64 & 8.64 & Passed \\
\hline Area up to max GZ & $3.150 \mathrm{~m} . \mathrm{deg}$ & 7.67 & 9.03 & 10.39 & Passed \\
\hline Angle of vanishing stability & $35 \mathrm{deg}$. & 90 & 90 & 90 & Passed \\
\hline DF angle & $20 \mathrm{deg}$ & 56 & 56.5 & 57 & P \\
\hline
\end{tabular}

fore it can be concluded that the concave spline type has provided better intact stability than the other spline. However, the stability performance of all developed axe bow hull form does not look significantly different.

\section{CONCLUSIONS}

The development of the axe bow hull forms for the patrol boat to support the surveillance activities on the territorial sea of Indonesia has been made. The principal dimension was obtained through the development of the linear regression equation, which is created from the selected reference boat. The design of the monohull for fish processing vessel was made. The hull geometry configurations have been proposed on the variation of the depth of bow and the water line spline type. The numerical calculations have been presented the resistance and the intact stability performance that can be used as recommendations and suggestions on their implementations.

In the case of resistance performances, the depth of bow and the spline types have no significant influence on the total resistance performance. However, it can be found that the convex type with the depth of bow $30 \% \mathrm{~T}$ has presented the lowest total resistance on the high service speed condition, and the straight type with the depth of bow $30 \% \mathrm{~T}$ was the lowest one on the slightly moderate service speed. Otherwise, all of the developed hulls have presented similar resistance on the low service speed.

Both parameters also do not have a significant influence on intact stability performance. However, the concave type with the depth of bow $50 \%$ T has presented a better intact stability performance than the others. Regarding the intact stability criteria, all of the developed hulls form fulfilled the requirement of the US coast guard standard. Therefore the developed axe bow hulls can be reliably adopted as the patrol boat hull form to support the surveillance activities.

\section{ACKNOWLEDGEMENT}

This work was funded by the directorate of research and public service 2020, through the Higher Education Ex- 
cellent Fundamental Research Scheme-2020 (penelitian dasar unggulan perguruan tinggi-2020).

\section{REFERENCES}

1. Directorate General of Marine and Fisheries Resources Surveillance (2019). Grand Design of Fisheries Boat Demand. Ministry of marine and fisheries, Jakarta.

2. Keuning, J.A., Pinkster, J. (1995). Optimisation of the seakeeping behaviour of a fast monohull. in FAST' 95, pp. 179-192.

3. Keuning, J.A., Pinkster, J. (1997). Further design and seakeeping investigations into the "Enlarged Ship Concept". in FAST' 97, pp. 201-207.

4. Damen Shipyard. Executive Summary Stan Patrol 4207, from https://www.damen.com/-/media/Products/Images/Clusters-groups/High-Speed-Crafts/ Stan-Patrol-Vessel/Stan-Patrol-4207/Documents/ Executive-Summary_Stan_Patrol_4207.pdf, accessed on 2020-06-08.

5. Keuning, J.A., Pinkster, J., van Walree, F. (2002). Further Investigations into the Hydrodynamic Performance of the AXE Bow Concept. The 6th Symposium on High Speed Marine Vehicles (WEMT 2002), pp. 1125-1138.

6. Keuning, J.A., van Walree, F. (2006). The Comparison of The Hydrodynamic Behavior of Three Fast Patrol Boats with Special Hull Geometries. The 5th International Conference on High Performance Marine Vehicles.

7. Keuning, J.A. (1992). Nonlinear Heave and Pitch Motions of Fast Ships in Irregular Head Waves. in ASNE High Speed Marine Vehicles Conference.

8. Keuning, J.A. (1994). The Non Linear Behavior of Fast Monohulls in Head Waves. PhD Thesis, Delft University of Technology, Den Haag.

9. Keuning, J.A., Pinkster, J., Toxopeus, S.L. (2001). The Effect of Bow Shape on the Seakeeping Performance of a Fast Monohull. FAST 2001, The 6th International Conference on Fast Sea Transportation, Southampton.

10. Keuning, J.A., Visch, G. (2009). The Application of a Vertical Bow Rotor on an AXE Bow. in FAST Conference Athens, Greece.
11. Keuning, J.A.,Gelling, J.L. (2007). The influence of the bow shape on the operability of a fast ship in a seaway. The 2nd International Conference on Marine Research and Transportation, Naples, 2007, pp. 219-234.

12. Gelling, J.L. (2006). The Axe Bow: The Shape of Ships to Come. The 19th International HISWA Symposium on Yacht Design and Yacht Construction, Amsterdam, pp. 1-10.

13. Poundra, G.A.P., Utama, I.K.A.P., Hardianto, D., Suwasono, B. (2017). Optimizing Trimaran Yacht Hull Configuration Based on Resistance and Seakeeping Criteria. Procedia Engineering, Vol. 194, pp. 112 119.

14. Ferrandis, J.A, Brizzolara, S., Chryssostomidis, C. (2018). Influence of large hull deformations on the motion response of a fast catamaran craft with varying stiffness. Ocean Engineering, vol. 163, pp. 207222.

15. Dumortier, C., Bonnet, J.F., Regnier, N., Ousten, Y. (2019). Comparing results of a power prediction tool with measured data from a series of 35 boats. Ocean Engineering, vol. 178, pp. 501-516.

16. De Luca, F., Pensa, C. (2019). The Naples Systematic Series - Second part: Irregular waves, seakeeping in head sea. Ocean Engineering, vol. 194.

17. Caramatescu, A., Mocanu, C.I. (2019). Experimental and numerical evaluation of wave impact stress on a composite boat hull. Materials Today: Proceedings, vol. 12, pp. 440-445.

18. Niklas, K., Pruszko, H. (2019). Full scale CFD seakeeping simulations for case study ship redesigned from V-shaped bulbous bow to X-bow hull form. Applied Ocean Research, vol. 89, pp. 188-201.

19. Tavakoli, S., Bilandi, R.N., Mancini, S., DeLuca, F., Dashtimanesh, A. (2020). Dynamic of a planing hull in regular waves: Comparison of experimental, numerical and mathematical methods. Ocean Engineering, vol. 217.

20. Bilandi, R. N., Vitiello, L., Mancini, S., Nappo, V., Roshan, F., Tavakoli, S., Dashtimanesh, A. (2020). Calm-water performance of a boat with two swept steps at high-speeds: Laboratory measurements and mathematical modeling. Procedia Manufacturing, vol. 42, pp. 467-474. 
21. Yanuar, Ibadurrahman, I., Gunawan, A., Wibowo, R.A., Gunawan. (2020). Drag reduction of X-pentamaran ship model with asymmetric-hull outrigger configurations and hull separation. Energy Reports, vol. 6, pp. 784-789.

22. Mitchell, J.H. (1898). The wave resistance of a ship. Philosophical Magazine, London, series 5, vol. 45, no. 272, pp. 106-123.

23. Wigley, W.C.S. (1933). A comparison of experimental and calculated wave-profiles and wave resistances for a form having parabolic waterlines. Royal Philosophical Society, London, 144.

24. Eggers, K. (1955). Resistance components of twobody ships. Jahrbuch der Schiffbautechnischen Gesellschaft, 49.
25. Tuck, E.O. (1987). Wave resistance of thin ships and catamaran. Unaltered October 1997 reprint of internal report T8701, University of Adelaide.

26. Couser, P., Wellicome J.F., Molland, A.F. (1998). An improved method for the theoretical prediction of the wave resistance of transom-stern hulls using a slender body approach. International Shipbuilding Progress, vol. 45, No. 444.

27. Larsson, L., Raven, H.C. (2010). Ship Resistance and Flow. The society of naval architects and marine engineers, New Jersey. 